\title{
CORRECTIVE GYMNASTICS AND SWIMMING FOR PRESCHOOL CHILDREN WITH POOR POSTURE
}

\author{
Daniela Sadikova \\ National Sports Academy „Vassil Levski”, Sofia, Bulgaria
}

\begin{abstract}
Introduction: Combination of swimming and corrective gymnastics is a widely used method of influencing poor posture among children. We use this combined therapeutic program in our practice since 2016.

Purpose: The aim of this study is to track the impact of the program on preschool children for a period of 3 months. Clinical material: The sample consisted of 78 healthy pupils aged 6-7. We used the New York Posture Rating Chart to evaluate the posture and Mini BESTest to measure the balance. The selected 78 pupils were randomly assigned into two groups: experimental and control. The experimental group performed a combined program of swimming twice a week, and gymnastics once a week for a period of 3 months.

Results: All pupils from the experimental group reported significant improvements in their posture compared with the controls. Only 12 children from the control group improved their posture. 28 children from the experimental and 24 from the control group improved their balance.

Conclusions: Combined swimming and corrective gymnastics program have been proven to be an effective method of responding to poor posture among preschool children.
\end{abstract}

Key words: corrective gymnastics, adapted swimming, preschool children

\section{INTRODUCTION}

Posture may be described as the composition of the positioning of all body segments at a given point in time and it's an important health indicator (McEvoy, et al., 2005). Various studies produced evidence that poor posture is widespread among Bulgarian children (Popova-Dobreva et al., 2008) and poor posture is a functional problem of the motor habit of posture (Dimitrova, 2006) Maintaining of upright position of a body is a problem of a balance and it could be gained by complex impact of visual and vestibular systems (Kottke, 1980, Hardy et al., 1984). The majority of people are born with proper postural alignment but begin exhibiting improper postural alignment past age 2 for a variety of reasons. (Rhodes, 1996). In an optimal alignment, it is expected that the muscles and joints are in dynamic balance, generating a minimal amount of effort and overhead, which leads to the optimum efficiency of the musculoskeletal system. In this sense, postural assessment is fundamentally important for diagnosing, planning, and monitoring the progress and results of physiotherapy (Zagyapan et al., 2012). There are also intrinsic and extrinsic factors that can influence a child's posture, such as heredity, environment or physical conditions under which the child lives, level of physical activity, socioeconomic level, emotional factors and physiological abnormalities due to human growth and development
(Chansirinukor et al., 2001, Grimmer et al. 1999, Mackenzie et al., 2003). According the third law of Newton this is the state of an object or body when the resultant force acting upon it equals zero (Bell, 1998). Human balance refers to the ability of not falling over and is related to center of gravity $(\mathrm{CoG})$ and the base of support (BoS). Postural control is the act of maintaining, achieving or restoring a state of balance during a given posture or activity (Pollock, 2000). Stability tasks can be considered static, when the body is stationary (e.g. when sitting or standing on a stable surface), or dynamic, when the body is moving, either during self-initiated internal perturbations (e.g. walking), or in response to external perturbations initiated by other people or objects (e.g. being pushed, or maintaining a stance on a moving bus) (Santos, 2010).

Aim and objectives of the study: The aim of this study is to track the impact of the combined therapeutic program of swimming and corrective gymnastics on preschool children with poor posture for a period of 3 months.

\section{METHODS}

Contingent of the study: The trial was conducted at № 84 Kindergarten "Detelina" in Sofia. The enrolment period was from March 2018 to May 2018. The last follow-up was in June 2018. All parent's sign 
of written consent before conducting the study. Exclusion criteria was: (1) severe spinal disorders, (2) cerebral palsy, (3) history of recent musculoskeletal injuries (5) autistic spectrum disorders and (6) and lack of parental informed consent. A baseline full medical history was obtained. Demographic information was taken - subject's age, height and weight. The sample consisted of 78 pupils with poor posture: 34 girls $(n=34$; mean age $6.1 \pm 0.5$ years; mean height $=118 \pm 7 \mathrm{~cm}$; mean weight $=22.2 \pm 3.6 \mathrm{~kg})$ and 44 boys ( $\mathrm{n}=44$; mean age $6.2 \pm 0.5$ years; mean height $=116 \pm 6 \mathrm{~cm}$; mean weight $=21.3 \pm 3.9 \mathrm{~kg}$ ) (Table 1). They were randomly assigned into two groups: experimental group (EG) and control group (CG). The EG performed a combined program of swimming (twice a week) and gymnastics (once a week) for a period of 3 months while the CG does not receive any specific treatment.

Table 1. Baseline demographic criteria and distribution

\begin{tabular}{|l|l|l|l|l|l|}
\hline $\begin{array}{c}\text { Contingent } \\
\text { of the study }\end{array}$ & Percentage & Average age & \multicolumn{1}{|c|}{ Height } & \multicolumn{1}{|c|}{ Weight } & $\begin{array}{c}\text { Groups } \\
\text { distribution }\end{array}$ \\
\hline Girls, $n=34$ & $34.5 \%$ & $6.1 \pm 0.5$ & $118 \pm 7 \mathrm{~cm}$ & $22.2 \pm 3.6 \mathrm{~kg}$ & $\begin{array}{l}E G ; n=14 \\
C G ; n=20\end{array}$ \\
\hline Boys, $n=44$ & $55.5 \%$ & $6.2 \pm 0.5$ & $116 \pm 6 \mathrm{~cm}$ & $21.3 \pm 3.9 \mathrm{~kg}$ & $\begin{array}{l}E G ; n=25 \\
C G ; n=19\end{array}$ \\
\hline
\end{tabular}

Assessment methods: Posture assessment was done by the 10-segment New York Posture Rating Scale (NYPR) - modification of the original NYPR (Howley, Franks., 1992) scoring 10,5,0 in order to assess 10 segments (head, shoulders, spine, hips, ankles, neck, upper back, trunk, abdomen, lower back). Each subject was assessed barefoot in standing position on the base of a platform and assumed a comfortable, erect posture with the body weight distributed between both feet. The plumb line was kept slightly anterior to right malleolus for assessing posture in sagittal plane and at midpoint between the feet for assessing in the frontal plane. Scoring was done as 10, 5, 0 for no deviation, some deviation and marked deviation respectively for each 10 criteria in the rating scale. Mini-BESTest - balance evaluation systems test was used to measure the balance (Leddy AL et al., 2011). The Mini-BESTest is a 14-item test, scored on a 3-level ordinal scale. The test assesses dynamic balance and includes 14 items addressing 4 sections: anticipatory postural adjustments, reactive postural control, sensory orientation and dynamic gait. The lower score result of item 3 - stand on one leg and item 6 - compensatory stepping correction - backward was taken. Both tests were performed by a physical therapist according to the original test instructions.

Therapeutic program: The EG performed $30 \mathrm{mi}-$ nutes swimming class twice a week and one-hour corrective gymnastics once a week. The therapeutic swimming class included warm-up activities consisted of arm circles, brisk walking, jumping jacks, standing knee lifts and exercises on a balance board. The activities in the water included water jogging and jump outs, kickboard kicks both in prone and supine, freestyle laps with focus in good form and exercises with noodle to cool down. The corrective gymnastic program was based on exercises for core strengthening: plank, bringing, wheelbarrow walking; different positions were used: prone, side lying, supine and quadruped and exercises through different games with and without obstacles. Every gymnastic class ended up with stretching exercises. The CG does not receive any specific exercise program or treatment.

\section{RESULTS}

Single time measurement and data collected was analyzed using New York Posture Rating Chart. The most significant difference was measured in the abdominal segment with improvement of 60 points (14 children from the EG improved their performance, while the others retained their high initial values). Seven segments - head, shoulders, spine, hips, neck, upper back and lower back showed slight difference and only two segments - ankles and trunk showed no difference between the EG and CG (Figure 1). 


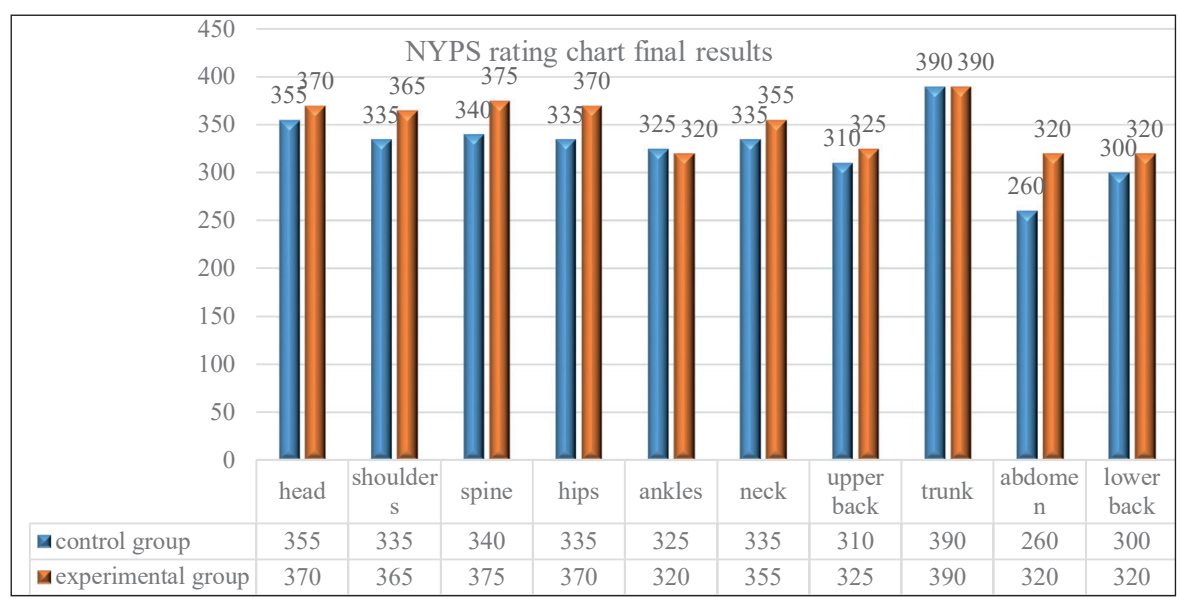

Figure 1. New York Posture Rating Chart segment-based results

The overall score of the NYPR chart showed significant improvement (230 points) of the EG compared to the CG. Despite the slight improvement

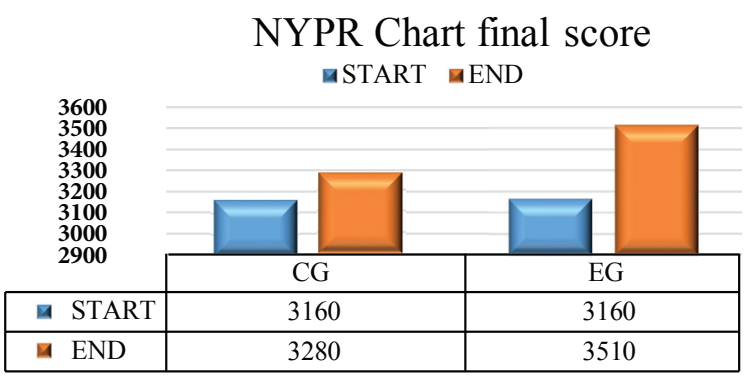

Figure 2. Overall score comparison in NYPR chart for CG and EG

The MiniBESTest results showed improvement for the EG in the sections of sensory orientation and dynamic gait, slight improvement on the anticipatory postural adjustments section and no improvement in the reactive postural control (Figure 3).

According to the total score of the MiniBESTest the in the individual test segments, the overall result shows a significant improvement in body posture (Figure 2).

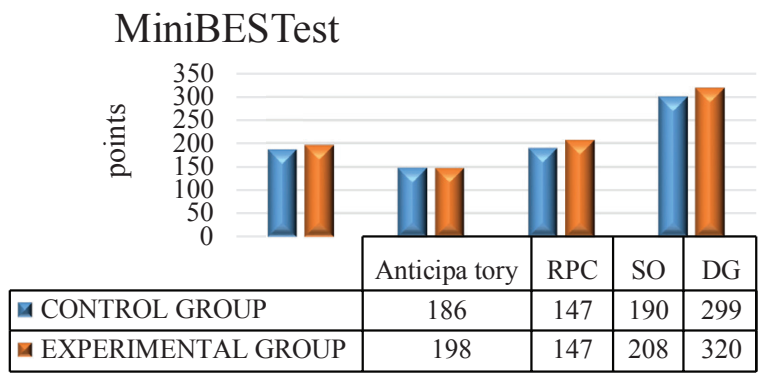

Figure 3. Changes in the different sections of MiniBESTest

EG shows significant balance improvement related to the CG (Figure 4).

The results of our study are similar to (Torlakovic et al., 2012), which considered that combined program of corrective gymnastic and therapeutic swimming can improve children's posture.

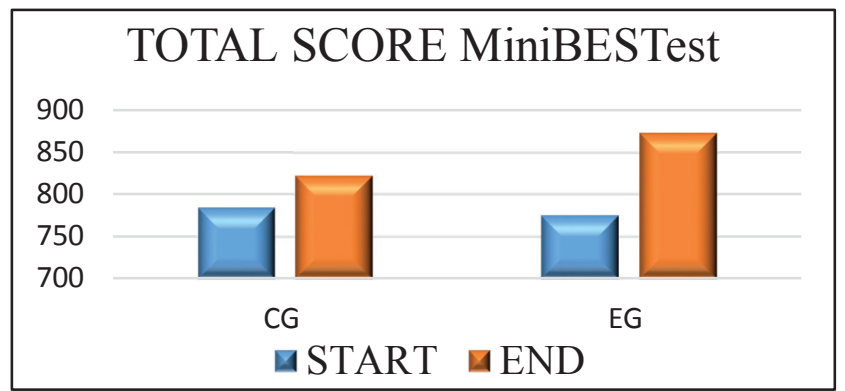

Figure 4. Before and after results in MiniBESTest for CG and EG.

\section{DISCUSSION}

The main objective of this study was to investigate the effects of corrective exercises and swimming to the body posture and balance among preschool children. The outcomes of this study clearly show that posture and balance parameters have improved. Similar conclusions were also reached by other authors who believe that it is possible to improve the body posture to a considerable extent by implementing adequate motion/movement programs (Torlakov- 
ić, 2012, Getz et al.,2006). Otherwise there are not many studies exploring combined therapy and we still do not have enough data about the spontaneous improvement. Corrective gymnastics and therapeutic swimming are used therapeutic method within many preschoolers including those with postural asymmetry, but there have been only a few attempts to prove their effectiveness. Although, research in this young age group is difficult because the protocol of the asymmetry model is not clear.

\section{CONCLUSIONS}

In conclusion, the current study suggests that corrective gymnastics and therapeutic swimming can be useful in order to improve posture and balance within preschool children. The advantages of the aquatic environment could be beneficial for children with poor posture, and these therapeutic methods can be applied in this young age group.

\section{REFERENCES}

Bell, F. (1998). Principles of Mechanics and Biomechanics. Nelson Thornes 1998, Cheltenham

Chansirinukor, W., Wilson, D., Grimmer, K., Dansie, B. (2001). Effects of backpacks on students: measurement of cervical and shoulder posture. Aust J Physiother: 47(2):110

Dimitrova, E. (2006). Kineziterapia pri grubnachni deformiteti i posturalni narushenia. Vo N. Popov (Ur.) Kinezaterapia $v$ sportnata praktika (str. 128-150), Sofia: NSA Press.

Getz, M., Hutzler, Y., Vermeer, A. (2006). The relationship between aquatic independence and gross motor function in children with neuro-motor impairments. Journal Adapted Physical Activity Quarterly; 23:339-355. Grimmer, KA., Williams, MT., Gill, TK. (1999). The associations between adolescent head-on-neck posture, backpack weight, and antropometric features. Spine. 1999;24(21):2262

Hardy, R. N., Hobsley, M. (1984). Neurophysiology, Aspen publishers, London

Kottke, F. J. (1980). Reflex patterns initiated by secondary sensory fiber endings of muscle spindles: Proposal. Arch Phys Med Rehabil, 56:1-7.

Mackenzie, WG., Sampath, JS., Kruse, RW., Sheir-Neiss,
GJ. (2003). Backpacks in children. Clin Orthop Relat Res.; 409:78-84.

McEvoy, MP., Grimmer, K. (2005). Reliability of upright posture measurements in primary school children. $B M C$ Musculoskelet Disord.; 29; 6:35.

Mikkelsson, M., Salminen, JJ., Sourander, A., Kautiainen, H. (1998). Contributing factors to the persistence of musculoskeletal pain in preadolescents: a prospective 1-year follow-up study. Pain. 1998;77(1):67-72.

Niemi, S., Levoska, S., Kemilä, J., Rekola, K., Keinänen-Kiukaanniemi, S. (1996). Neck and shoulder symptoms and leisure time activities in high school students. Journal of Orthopedic Sports Physical Therapy 1996;24(1):25-9.

Pollock, AS., et al. (2000). "What is balance?" Clinical Rehabilitation 14.4 (2000): 402-406.13.

Popova-Dobreva, D, Gencheva, N., Markovska, G. Genchev, K. (2008). Razprostranenie na nepravilna stojka i grubnachni izkrivqnaniq v nachalna uchilishtna stepen. Sp."Kineziterapia, br.1/2008, str.20-24. ISBN 1311-770X

Rhodes, M. (1996, January/February). Back in balance. Women's Sports \& Fitness. 1996, 18, 44-48

Santos, MJ., Kanekar, N., Aruin, AS. (2010). The role of anticipatory postural adjustments in compensatory control of posture: 1. Electromyographic analysis. Journal of Electromyographic Kinesiology 2010; 20: 388-97

Torlaković, A., Simikić, I., Muftić, M. (2012). The effects of the combined exercise in water and on land on body posture of preschool children. 17th Congress of ECSS 2012, Bruges, Belgium;17:314

Leddy, AL., Crowner, BE., Earhart, GM. (2011). Utility of the Mini-BESTest, BESTest, and BESTest Sections for Balance Assessments in Individuals with Parkinson Disease. J Neurol Phys Ther. 2011 Jun;35(2):90-7. doi: 10.1097/NPT.0b013e31821a620c.

Widhe, T. (2001). Spine: posture, mobility and pain. A longitudinal study from childhood to adolescence. Eur Spine J. 2001;10(2):118-23.

Corresponding author: Sadikova Daniela, $\mathrm{PhD}$ student Department of Kinesitherapy and Rehabilitation National Sports Academy "Vassil Levski" E-mail: daniela.sadikova@gmail.com 